Analysis of bulk heterojunction organic solar cell blends by solid-state NMR relaxometry and sensitive external quantum efficiency - Impact of polymer side chain variation on nanoscale morphology

Peer-reviewed author version

DEVISSCHER, Dries; REEKMANS, Gunter; KESTERS, Jurgen; VERSTAPPEN, Pieter; Benduhn, Johannes; Van den Brande, Niko; LUTSEN, Laurence; MANCA, Jean; VANDERZANDE, Dirk; VANDEWAL, Koen; ADRIAENSENS, Peter \& MAES, Wouter (2019) Analysis of bulk heterojunction organic solar cell blends by solid-state NMR relaxometry and sensitive external quantum efficiency - Impact of polymer side chain variation on nanoscale morphology. In: ORGANIC ELECTRONICS, 74, p. 309-314.

DOI: $10.1016 /$ j.orgel.2019.06.046

Handle: http://hdl.handle.net/1942/29634 


\title{
Analysis of Bulk Heterojunction Organic Solar Cell Blends by Solid-State NMR Relaxometry and Sensitive External Quantum Efficiency - Impact of Polymer Side Chain Variation on Nanoscale Morphology
}

\author{
Dries Devisscher, ${ }^{1,2}$ Gunter Reekmans, ${ }^{1,2}$ Jurgen Kesters, ${ }^{1,2}$ Pieter Verstappen, ${ }^{1,2}$ Johannes \\ Benduhn, ${ }^{3}$ Niko Van den Brande, ${ }^{4}$ Laurence Lutsen, ${ }^{2}$ Jean Manca, ${ }^{5}$ Dirk Vanderzande, ${ }^{1,2}$ Koen \\ Vandewal, ${ }^{1,2}$ Peter Adriaensens ${ }^{1,2}$ and Wouter Maes ${ }^{1,2, *}$ \\ ${ }^{1}$ UHasselt - Hasselt University, Institute for Materials Research (IMO-IMOMEC), Agoralaan 1, 3590 \\ Diepenbeek, Belgium \\ ${ }^{2}$ IMEC, IMOMEC Division, Wetenschapspark 1, 3590 Diepenbeek, Belgium \\ ${ }^{3}$ Institut für Angewandte Photophysik, Technische Universität Dresden, Germany \\ ${ }^{4}$ Vrije Universiteit Brussel, Pleinlaan 2, 1050 Brussels, Belgium \\ ${ }^{5}$ UHasselt - Hasselt University, X-LAB, Agoralaan 1, 3590 Diepenbeek, Belgium
}

\begin{abstract}
A significant number of organic electronic devices rely on blends of electron-donating and electron-accepting molecules. In bulk heterojunction organic photovoltaics, the nanoscopic phase behavior of the two individual components within the photoactive layer has a major impact on the charge separation and charge transport properties. For polymer:fullerene solar cells, it has been hypothesized that an increased accessibility of the electron-deficient monomer unit in push-pull type low bandgap polymers allows for fullerene 'docking'. The close proximity of electron donor and acceptor molecules enables more efficient charge transfer, which is beneficial for the device efficiency. With this in mind, we synthesized a series of PBDTTPD [poly(benzodithiophene-thienopyrroledione)] low bandgap copolymers with varying side chains. Solar cells were fabricated for all polymers and the device characteristics were compared. The combination of proton wideline solid-state NMR (sSNMR) relaxometry and sensitive external quantum efficiency (SEQE) measurements was shown to provide essential information on donor-acceptor interactions and phase separation in bulk heterojunction organic photovoltaics. The reduced charge transfer state absorption and the observed phase separation of crystalline $\mathrm{PC}_{71} \mathrm{BM}$ domains for the polymers containing the most accessible methyl-TPD unit indicate a diminished contact between donor and acceptor, leading to a loss in performance.
\end{abstract}

Keywords: push-pull copolymers, side chain variation, blend morphology, solid-state NMR relaxometry, external quantum efficiency 


\section{Introduction}

Over the last two decades, bulk heterojunction (BHJ) organic solar cells have evolved into an attractive photovoltaic technology, showing several promising features such as the ability to be processed and printed from solution on inexpensive flexible substrates, a good performance in low light conditions, aesthetic versatility, low weight and (semi)transparency.[1-4] Even though the power conversion efficiency (PCE) of BHJ organic photovoltaics (OPVs) has noticeably increased in recent years, particularly by the development of novel non-fullerene acceptors,[5-10] some fundamental aspects related to the nanomorphology of the $\mathrm{BHJ}$ active layer need further attention.

As the photoactive layer consists of two finely intermixed components, an electron donor and an electron acceptor, the molecular arrangement of these materials has a major influence on the underlying physical properties that govern processes such as exciton dissociation, charge separation and charge transport. Although microscopic techniques such as scanning electron microscopy (SEM), transmission electron microscopy (TEM) and atomic force microscopy (AFM) can provide useful information on the active layer morphology, these techniques suffer from some drawbacks. SEM and AFM only probe the surface of the layer, while TEM requires appropriate preparation methods to obtain free standing, thin, electron transparent films. In some cases, these techniques cannot properly distinguish the separate phases due to a lack of microscopic contrast. On the other hand, sensitive external quantum efficiency (sEQE) measurements of the charge transfer (CT) absorption band and solid-state NMR (sSNMR) spectroscopy and relaxometry are powerful techniques that do not suffer from these drawbacks and that can provide essential information on photovoltaic bulk heterojunction blends.

CT absorption band measurements are a rather easy way to probe donor-acceptor interactions and their contact area directly on photovoltaic blends and/or devices. Indeed, changes in donor-acceptor contact area are reflected in changes in the intensity of the CT absorption band.[11] Such weak CT absorption occurs at photon energies below the optical gap of both the donor and acceptor and can be quantified by sensitive measurements of the blend's absorption spectrum or external quantum efficiency spectrum, which both have been shown to correlate with the amount of donor-acceptor interface area.[12]

ssNMR spectroscopy and relaxometry can be used to investigate the molecular miscibility of polymer-based material blends and to identify phase separation down to $10 \mathrm{~nm}$ sized domains inside the bulk of the layer.[13-17] Mens et al. first demonstrated the usefulness of ${ }^{1} \mathrm{H}$ wideline ssNMR relaxometry for the analysis of OPV blends by quantifying the amount of $\mathrm{PC}_{61} \mathrm{BM}$ fullerene phase separating into crystalline domains in an MDMO-PPV:PC 61 BM system, using different weight ratios, solvents and casting techniques.[18, 19] Nieuwendaal et al. also applied this technique to study the phase separation in a $\mathrm{P} 3 \mathrm{HT}: \mathrm{PC}_{61} \mathrm{BM}$ blend upon annealing at different temperatures.[20] In a follow-up study, the same group reported that ${ }^{1} \mathrm{H}$ spin 
diffusion data can be used to estimate domain size distributions and that a significant population of domains of tens of nanometers in size is a common characteristic of samples affording higher efficiencies.[21] More recently, they applied the advanced Rotational Echo Double Resonance NMR technique to demonstrate that, although a $\mathrm{P} 3 \mathrm{HT}: \mathrm{PC}_{61} \mathrm{BM}$ blend film may appear homogenous at $6 \mathrm{~nm}$ scale through ${ }^{1} \mathrm{H}$ spin diffusion measurements, pure $\mathrm{PC}_{61} \mathrm{BM}$ clusters are formed on a $3 \mathrm{~nm}$ scale. This technique also allowed to quantify the near-neighbor contacts between $\mathrm{P} 3 \mathrm{HT}$ and $\mathrm{PC}_{61} \mathrm{BM}$.[22] The only effort so far to apply ${ }^{1} \mathrm{H}$ wideline ssNMR relaxometry to a push-pull type copolymer blend has been by Chambon et al.,[23] who analyzed the influence of the octanedithiol additive on the morphology of a PCPDTBT:PC ${ }_{61} B M$ blend.

The electron donor material in state-of-the-art BHJ OPV devices is very often a semiconducting push-pull type copolymer, consisting of electron-rich heteroaromatic units alternating with electron-deficient moieties. This combination lowers the bandgap and broadens the absorption profile. Interestingly, the highest occupied molecular orbital (HOMO) tends to be delocalized over the conjugated polymer backbone, while the lowest unoccupied molecular orbital (LUMO) is rather localized on the pull monomer.[24] It has been postulated that polymers that include electron-deficient units that are highly accessible (i.e. no bulky alkyl side chains) to the fullerene acceptor tend to show better OPV efficiencies as the charge is more easily transferred to the electron-accepting fullerene.[25] An example of this effect from our own work is the study by Verstappen et al.,[26] who showed that the complete removal of the side chains from the electron-deficient quinoxaline unit in a PCDPTQx polymer led to a significant change in blend morphology and enhanced PCE values. However, it remains unclear if this approach can really be used as a general design concept for high-performance OPV blends.

Among the push-pull type copolymers affording best device efficiencies, the family based on benzo[1,2- $b ; 4,5-b^{\prime}$ ]dithiophene (BDT) has been widely utilized.[27] BDT is synthetically easily accessible and its electron-rich rigid and planar structure with a highly delocalized $\pi$-system has been shown to reduce the optical gap and favor hole transport.[1] Combined with the thienopyrrolodione (TPD) pull monomer, PCEs up to $8.3 \%$ have been reached.[28] PBDTTPD polymers also exhibit a high thermal and photostability, attributed to the alkoxy side chains and the well-organized structure mitigating the photodegradation process.[29] Due to its relatively low synthetic complexity,[30] this polymer is also a suitable candidate for industrial upscaling, as was demonstrated by a convenient continuous flow protocol.[31]

Side chain variation has already been an extensive point of attention for the PBDTTPD:PC ${ }_{71} B M$ system. Piliego et al. and You et al. demonstrated that the introduction of linear instead of branched alkyl side chains on the TPD monomer enhanced the photovoltaic properties. In both cases, the best results were achieved for the 2-ethylhexyl(BDT)-octyl(TPD) combination.[32, 33] Cabanetos and co-workers reported that linear side chains on the BDT monomer are detrimental to the self-assembly and backbone orientation of the polymer in 
thin films. They also demonstrated that a shortening of the TPD side chain can be beneficial for the photovoltaic performance. The best result was achieved with the 2-ethylhexyl(BDT)heptyI(TPD) combination, while further reducing the TPD side chain to hexyl led to solubility issues.[28] Building on this, Labban et al. investigated several other side chain combinations.[34] Through grazing-incidence wide-angle $x$-ray scattering (GIWAXS) measurements, they observed a clear impact on the crystallite orientation and order upon variation of the alkyl side chain pattern. The 2-ethylhexyl(BDT)-octyl(TPD) combination showed a clear preference for a face-on orientation, whereas the polymers with longer linear BDT (e.g. hexadecyl, octadecyl) and shorter TPD (e.g. butyl, ethyl) substituents were more inclined to afford less crystalline materials with an edge-on orientation. In this study, however, no blends with fullerenes were prepared and these materials were not tested for their photovoltaic properties. Dyer-Smith and colleagues studied two PBDTTPD polymers, one with two long linear quaterdecyl chains and the other with 2-ethylhexyl and heptyl on the BDT and TPD monomer, respectively. They observed significantly lower recombination losses for the branched-linear combination, leading to a significantly higher current.[35] Finally, Graham et al. used solid-state two-dimensional ${ }^{13} \mathrm{C} /{ }^{1} \mathrm{H}$ heteronuclear correlation (HETCOR) NMR to analyze the spatial proximity of the fullerene acceptor to the TPD monomer for several PBDTTPD side chain combinations. They demonstrated that a longer (tetradecyl) or branched (2-ethylhexyl) side chain on TPD disrupted the contact with fullerene. Devices based on these materials exhibited significantly reduced photovoltaic properties, which supported their hypothesis that improved intermolecular interactions and proximity between the electron donor and acceptor materials can contribute to improved performance for OPV systems. [25]

Following this reasoning, a new series of PBDTTPD polymers was designed, synthesized and characterized in this work. The shortest possible alkyl side chain (i.e. a methyl group) was applied on the electron-deficient TPD monomer to increase its steric accessibility toward the fullerene electron acceptor. The solubility issues that arise from this were overcome by the substitution of half or all of the 2-ethylhexyl side chains on the BDT monomer by longer 3butylnonyl or 2-octyldodecyl substituents (Figure 1). Longer branched rather than linear alkyl side chains were selected for the BDT monomer because of the reported negative impact of linear side chains. Furthermore, two polymers were designed to contain either 10 or $20 \%$ methyl groups on the TPD monomer, while maintaining 2-ethylhexyl side chains on BDT. The new materials were applied in OPV devices and the active layer blends were investigated using SEQE measurements and SSNMR relaxometry. We find that the introduction of methyl-TPD leads to a loss in solar cell efficiency in all cases. The SEQE measurements indicate a diminished contact between the donor and acceptor, particularly for the polymers containing 3butylnonyl side chains on the BDT monomer, whereas ssNMR relaxometry reveals significant phase separation of crystalline $\mathrm{PC}_{71} \mathrm{BM}$ domains in the blends that exhibit lower performance. 


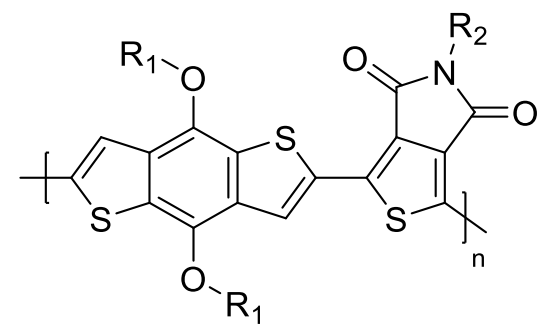

P1: $R_{1}=$ 2-ethylhexyl, $R_{2}=$ octyl

P2: $R_{1}=\left(2\right.$-ethylhexyl) $0.5:(3-\text { butylnonyl })_{0.5}, \mathrm{R}_{2}=$ methyl

P3: $R_{1}=3$-butylnonyl, $R_{2}=$ methyl

P4: $R_{1}=2$-octyldodecyl, $R_{2}=$ methyl

P5: $\mathrm{R}_{1}=2$-ethylhexyl, $\mathrm{R}_{2}=(\text { octyl })_{0.9}:(\text { methyl })_{0.1}$

P6: $\mathrm{R}_{1}=2$-ethylhexyl, $\mathrm{R}_{2}=(\text { octyl })_{0.8}:(\text { methyl })_{0.2}$

Figure 1: Overview of the synthesized PBDTTPD polymers with their respective solubilizing alkyl side chains.

\section{Results and Discussion}

The introduction of the various side chains on the BDT and TPD monomers was performed following literature procedures.[28, 36] Details can be found in the Supplementary data. All alternating copolymers were synthesized by Stille cross-coupling. Polymerizations were performed with $3 \mathrm{~mol} \% \mathrm{Pd}_{2} \mathrm{dba}_{3}$ and $12 \mathrm{~mol} \% \mathrm{P}(\mathrm{o} \text {-tol })_{3}$ in chlorobenzene at $110{ }^{\circ} \mathrm{C}$ for 16 hours. Following polymerization, residual palladium traces were removed by extraction with an aqueous sodium diethyldithiocarbamate solution, after which the polymers were separated into fractions with varying solubility (molar mass) using Soxhlet extractions.

The molar masses of the polymers were estimated via high-temperature gel permeation chromatography (Figure S1, Table S1). Since PBDTTPD is known for its strong aggregation tendency, aggregation peaks appeared at the high molar mass side of the chromatograms, reducing the accuracy of the determined values. Nevertheless, all molar masses were in the same range $\left(M_{\mathrm{n}}=10-15 \mathrm{~kg} \mathrm{~mol}^{-1}\right)$, avoiding complications due to different polymer chain lengths. The electrochemical properties of the polymers (as thin films) were investigated by cyclic voltammetry (CV) (Table S2). The onset potentials of oxidation and reduction were used to estimate the HOMO and LUMO, respectively. While the LUMO energy levels are similar for all materials, the observed HOMO values fluctuate within a range of $\pm 0.2 \mathrm{eV}$ as the polymer side chain pattern is varied. The decrease in the electrochemical bandgap for P2, P5 and P6 (as a result of their higher HOMO) is not reflected in the optical gap (as derived from the onset of absorption in the UV-Vis spectra, Figure S2), which remains close to $1.85 \mathrm{eV}$ in all cases.

The photovoltaic properties of the PBDTTPD polymer donor materials were then assessed by blending them with phenyl- $\mathrm{C}_{71}$-butyric acid methyl ester $\left(\mathrm{PC}_{71} \mathrm{BM}\right)$ and applying these blends as photoactive layers in BHJ polymer solar cells with a traditional device architecture 
glass/ITO/PEDOT:PSS/active layer/Ca/Al. The solar cell parameters of the optimized devices are summarized in Table 1 (while our optimization efforts are listed in Table S3). No data were acquired for $\mathbf{P 4}$ as no properly functioning solar cell could be fabricated from this polymer.

Table 1: Device parameters for the BHJ organic solar cells based on the different PBDTTPD:PC ${ }_{71} B M$ blends.

\begin{tabular}{|c|c|c|c|c|c|c|}
\hline & Processing solvent $^{a}$ & $V_{\text {oc }}(\mathrm{V})$ & $J_{s c}\left(m A c m^{-2}\right)$ & FF & Average PCE $^{\mathrm{b}}(\%)$ & Best PCE (\%) \\
\hline P1 & $\mathrm{CB}+5 \% \mathrm{CN}$ & 0.93 & 10.13 & 0.66 & 6.17 & 6.42 \\
\hline P2 & $\mathrm{ODCB}+5 \% \mathrm{CN}$ & 0.84 & 9.87 & 0.67 & 5.57 & 5.88 \\
\hline P3 & $C F+5 \%$ ODCB & 0.76 & 7.58 & 0.57 & 3.29 & 3.38 \\
\hline P5 & $\mathrm{CB}+5 \% \mathrm{CN}$ & 0.88 & 9.71 & 0.58 & 4.95 & 5.11 \\
\hline P6 & $C F+5 \%$ ODCB & 0.89 & 9.79 & 0.51 & 4.45 & 4.76 \\
\hline
\end{tabular}

${ }^{a}$ Chlorobenzene (CB), chloronaphthalene (CN), orthodichlorobenzene (ODCB), chloroform (CF).

${ }^{\mathrm{b}}$ Averages taken over 4 devices.

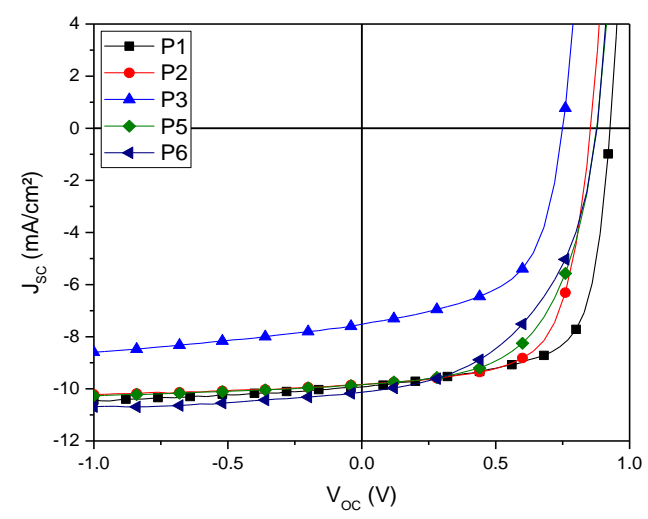

Figure 2: $J-V$ curves for the optimized (average performing) PBDTTPD solar cells.

We observed that the introduction of the methyl substituent on the TPD monomer did not improve the current-voltage $(J-V)$ parameters. When introducing methyl and $50 \% 3-$ butylnonyl substituents on the TPD and BDT monomers, respectively (P2), both the shortcircuit current $\left(J_{\mathrm{sc}}\right)$ and the open-circuit voltage $\left(V_{\mathrm{oc}}\right)$ diminished as compared to the reference blend based on P1. Completely replacing the 2-ethylhexyl side chains on the BDT moiety by 3butylnonyl (P3) further lowered both the $J_{s c}$ and $V_{o c}$, while the fill factor (FF) now dropped as well. With the introduction of only 10 or $20 \%$ methyl-TPD (P5 and P6, respectively), the $V_{\text {oc }}$ remained similar as compared to $\mathbf{P 1}$, but the PCE nevertheless diminished by the small decrease in $\mathrm{J}_{\mathrm{sc}}$ and a more drastic reduction in FF. The presented side chain combinations were not investigated in the previous study by Labban et al.[34] Nevertheless, it is reasonable to assume that at least part of the lower performance can be explained by a reduced crystallinity and tendency toward edge-on orientation, as was the case with their octadecyl-ethyl PBDTTPD. 
Interestingly, the observed strong reduction in $V_{\text {oc }}$ for the devices based on P3 cannot be explained by the almost invariant HOMO energy level as obtained by CV. As the $V_{\text {oc }}$ is related to the energy of the charge transfer state $\left(E_{C T}\right)$,[37] sEQE measurements were performed on the polymer: $\mathrm{PC}_{71} \mathrm{BM}$ devices (Figure 3). $E_{\mathrm{CT}}$ was determined as reported[37] and observed to be approximately $1.5 \mathrm{eV}$ for all samples, suggesting the loss in $V_{\text {oc }}$ has a different origin.

By normalizing the EQE spectra in the spectral region of $\mathrm{PC}_{71} \mathrm{BM}$ absorption, it becomes apparent that the CT state accounts for less absorption in case of the devices based on $\mathbf{P} 2$ and P3 (80\% and 60\%, respectively) as compared to the reference system based on P1, while this remains unchanged for $\mathbf{P 5}$ and $\mathbf{P 6}$. This implies a reduced presence of polymer: $P C_{71} B M$ interface in the blends with $\mathbf{P 2}$ and $\mathbf{P 3}$. The contact of the $P C_{71} B M$ acceptor with the donor polymer seems to be disrupted due to the change in side chain pattern. The improved accessibility of the TPD unit might be counteracted by the steric hindrance produced by the 3butylnonyl side chain on the BDT unit, although a more complex behavior related to the different mixing enthalpies cannot be excluded. This reduced interface between the donor and acceptor materials can be a possible explanation for the reduced $J_{s c}$ observed for these blends, as this can negatively impact exciton dissociation.

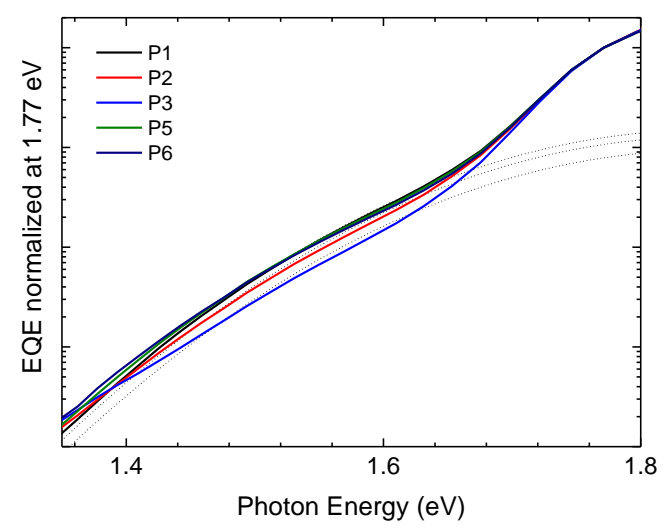

Figure 3: $\mathrm{SEQE}$ spectra for the PBDTTPD:PC $71 \mathrm{BM}$ solar cells, normalized at $1.77 \mathrm{eV}$ (i.e. the absorption range of $P C_{71} B M$, but in the gap of PBDTTPD). Colored lines display the EQE values, while the dotted lines represent a gaussian fit of the CT band. The reduction of the amplitude of the fit of the CT band indicates a reduced interface between the donor and acceptor materials. [37]

To investigate whether the reduced interface observed in the SEQE measurements is visible on a microscopic level, AFM topographic images of the active layer blends of the best performing solar cell devices were obtained (Figure 4). The layers composed of P1 or P2 and $\mathrm{PC}_{71} \mathrm{BM}$ show a finely intermixed morphology without distinct phase boundaries, whereas the active layer based on P3 displays deep cracks, signifying a less ideal BHJ and possible phase separation of the two components. The active layers based on P5 and P6 both display a low surface roughness which points to a relatively homogenously mixed blend. 
P1
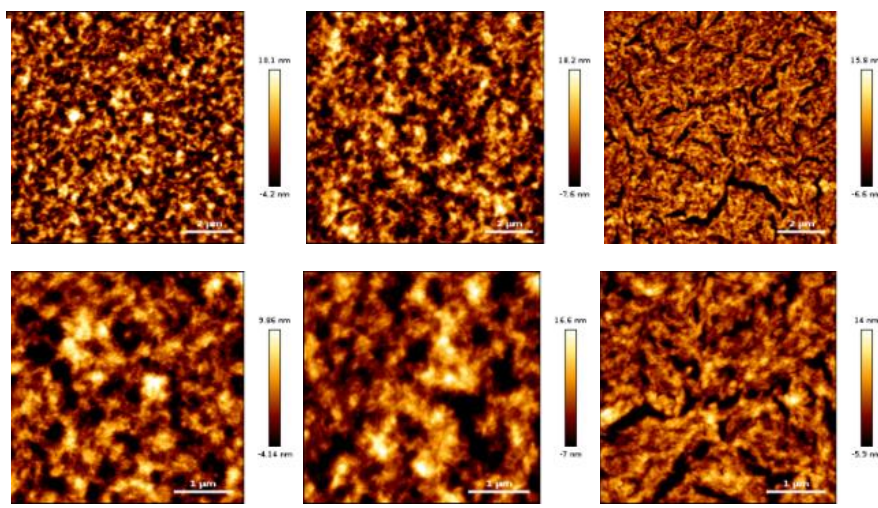

P3

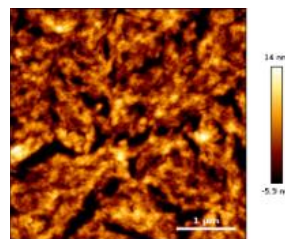

P5
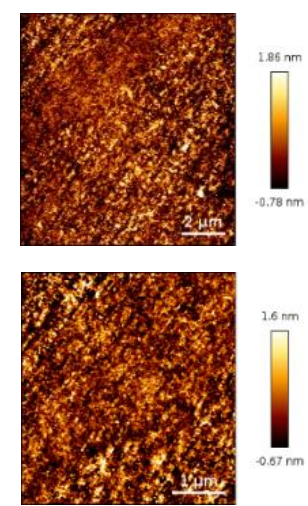

P6
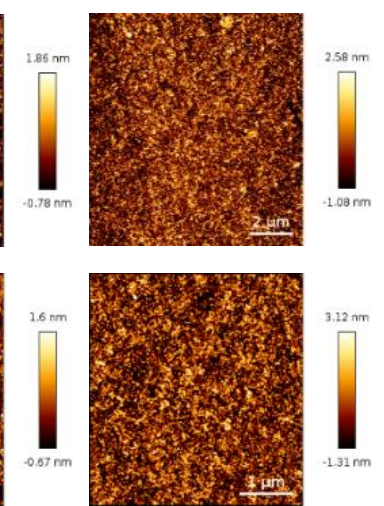

Figure 4: AFM images of the best performing active layer blends.

For a deeper insight into the morphology of the blend films at the nanometer scale, we used proton wideline ssNMR relaxometry as a fast and non-invasive analysis method. Two relaxation time constants were investigated in particular, $T_{1 \mathrm{H}}$ and $T_{1 \mathrm{pH}}$. The spin-lattice or $T_{1 \mathrm{H}}$ relaxation (in the order of seconds) is dominated by the spectral density of (segmental) chain motions in the $\mathrm{MHz}$ region, while the spin-lattice relaxation in the rotating frame or $T_{1 \mathrm{pH}}$ relaxation (in the order of milliseconds) is mainly affected by slower motions in the $\mathrm{kHz}$ region. In solid systems, both decay times are influenced by the process of spin diffusion (SD), in contrast to the fast (in the order of $\mu \mathrm{s}$ ) spin-spin or $T_{2 H}$ relaxation. [13] Proton SD is not a physical movement of protons but a transfer of nuclear spin energy by successive energyconserving nuclear spin flips. It allows to judge the degree of phase separation and to roughly estimate the size of phase-separated molecular domains. The maximum diffusive path length $L$ can be approximated by the following Fickian diffusion equation:

$L=\left(6 \cdot D \cdot T_{\mathrm{iH}}\right)^{1 / 2}$

(Eq. 1)

in which $T_{\mathrm{iH}}$ is the $T_{1 \mathrm{H}}$ or $T_{1 \rho \mathrm{H}}$ relaxation decay time and $D$ is the spin diffusion coefficient ( $4 \mathrm{x}$ $10^{-16} \mathrm{~m}^{2} \mathrm{~s}^{-1}$ for rigid organic polymer systems).[14]

Phase specific decay times are only observed if the domain sizes exceed the diffusive path length $L$. Otherwise, averaged values are obtained. The $T_{1 \mathrm{H}}$ relaxation (seconds) provides information regarding the miscibility on a distance scale in the order of tens to hundreds of $\mathrm{nm}$ and is a rather large-scale property. The faster $T_{1 \mathrm{pH}}$ relaxation (milliseconds) is used to study the morphology at the lower nanometer level, generally below $10 \mathrm{~nm}$.

Table 2 displays the relaxation results obtained for the pure blend components as well as for the PBDTTPD:PC ${ }_{71} B M$ films. The spin-lattice relaxation of pure $P C_{71} B M$ appears to be biexponential and can be separated into two decay times $\left(T_{1 H^{L}}\right.$ and $\left.T_{1 H^{S}}\right)$, of which the long and short decay time represent the more crystalline and more amorphous phase, respectively.[15, 
18,38 ] The origin of the long decay time can be found in the molecular motions being highly restricted in rigid crystalline environments, causing an inefficient $T_{1 \mathrm{H}}$ relaxation. Based on the value of the long decay time ( $2.31 \mathrm{~s}$ ), the average minimal dimension of the $\mathrm{PC}_{71} \mathrm{BM}$ crystalline domains can be estimated to be around $75 \mathrm{~nm}$. The pure polymers on the other hand all show a mono-exponential decay with a short $T_{1 \mathrm{H}}$ decay time characteristic for an amorphous state, which was confirmed by the presence of a glass transition temperature upon thermal analysis of the reference system $\mathbf{P} \mathbf{1}$ by rapid heat-cool calorimetry (Figure S4).

Table 2: Solid-state ${ }^{1} \mathrm{H}$ wideline $\mathrm{NMR}$ relaxation data for the individual blend components and PBDTTPD:PC ${ }_{71} B M$ films.

\begin{tabular}{|c|c|c|c|c|}
\hline Sample & $T_{1 \mathrm{H}^{\mathrm{s}}}(\mathrm{s})^{\mathrm{a}}$ & $T_{1 H^{L}}{ }^{\mathrm{L}}(s)^{\mathrm{a}}$ & $T_{1 \rho \mathrm{H}}^{\mathrm{s}}(\mathrm{ms})^{\mathrm{a}}$ & $T_{1 \rho H^{L}}(m s)^{a}$ \\
\hline $\mathrm{PC}_{71} \mathrm{BM}$ & $0.21(10 \%)$ & $2.31(90 \%)$ & $1.3(25 \%)$ & $13.0(75 \%)$ \\
\hline P1 & $0.72(100 \%)$ & - & $0.8(13 \%)$ & $3.3(87 \%)$ \\
\hline P2 & 0.75 (100\%) & - & 0.7 (23\%) & $2.3(77 \%)$ \\
\hline P3 & $0.73(100 \%)$ & - & $0.6(23 \%)$ & $2.0(77 \%)$ \\
\hline P5 & $0.72(100 \%)$ & - & $0.8(15 \%)$ & $3.3(85 \%)$ \\
\hline P6 & $0.75(100 \%)$ & - & $0.9(14 \%)$ & $3.2(86 \%)$ \\
\hline P1:PC ${ }_{71} \mathrm{BM}$ & $0.76(100 \%)$ & - & $1.0(25 \%)$ & $3.6(75 \%)$ \\
\hline P2: $\mathrm{PC}_{71} \mathrm{BM}$ & 0.85 (100\%) & - & 1.6 (56\%) & $8.1(44 \%)$ \\
\hline P3:PC ${ }_{71} B M$ & $0.86(100 \%)$ & - & $1.3(72 \%)$ & $10.1(28 \%)$ \\
\hline P5:PC ${ }_{71} B M$ & $0.82(100 \%)$ & - & $1.6(45 \%)$ & 7.1 (55\%) \\
\hline $\mathrm{P} 6: \mathrm{PC}_{71} \mathrm{BM}$ & $0.81(100 \%)$ & - & 1.7 (49\%) & $7.2(51 \%)$ \\
\hline
\end{tabular}

${ }^{\mathrm{a}}$ Error of $0.02 \mathrm{~s}$ on $T_{1 \mathrm{H}}$ and $0.2 \mathrm{~ms}$ on $T_{1 \rho \mathrm{H}}$.

The $T_{1 \rho \mathrm{H}}$ relaxation for pure $\mathrm{PC}_{71} \mathrm{BM}$ also displays a bi-exponential behavior. The short and long decay time again represent the amorphous and crystalline fractions, respectively. As the long $T_{1 \mathrm{H}}$ as well as the long $T_{1 \mathrm{pH}}$ decay time can be attributed to crystalline $\mathrm{PC}_{71} \mathrm{BM}$, the corresponding fractions ( 90 and $75 \%$ ) independently show that a pristine $\mathrm{PC}_{71} \mathrm{BM}$ film is highly crystalline. The $T_{1 \rho \mathrm{H}}$ relaxation of the pure polymers behaves also bi-exponentially, a typical behavior for polymers with long flexible side chains and for which the corresponding proton fractions cannot be easily assigned completely.[39] In this case, the two decay times do not represent phase separation but incomplete spin diffusion due to weakened dipolar interactions in the long flexible side chains. Since most of the polymer protons are situated in these side chains, the decay time with the largest proton fraction mainly represents these mobile chain segments (here $T_{1 \rho} \mathrm{H}^{\mathrm{L}}$ ). In contrast to pure $\mathrm{PC} \mathrm{C}_{71} \mathrm{BM}$, for which the fraction with the long $T_{1 \mathrm{pH}}$ decay time is associated with the rigid crystalline phase, the fraction with the long $T_{1 \rho \mathrm{H}}$ decay time for the polymers originates from the protons of the mobile side chains. This distinction can be easily explained as it originates from the large difference in correlation time of segmental motions in crystalline phases and flexible side chains. In a so-called correlation plot, showing relaxation decay times versus correlation time of segmental 
motions, the $\mathrm{PC}_{71} \mathrm{BM}$ crystals and flexible polymer side chains are situated on opposite sides of the minimum (Figure S5).

Regarding the $T_{1 \mathrm{H}}$ relaxation behavior of the polymer:fullerene blends, only a single short decay time is observed, which is only slightly longer compared to this found for the corresponding pure polymer films. Due to efficient spin diffusion, the $T_{1 \mathrm{H}}$ relaxation of the $\mathrm{PC}_{71} \mathrm{BM}$ protons occurs via the more efficient Larmor frequency (400 MHz) segmental chain motions of the polymers. This implies that the $\mathrm{PC}_{71} \mathrm{BM}$ nanocrystals present in these films must be smaller than about $45 \mathrm{~nm}$, as calculated with the SD equation (Eq. 1).

For the $T_{1 \mathrm{pH}}$ relaxation on the other hand, a bi-exponential behavior is observed. In the $\mathbf{P 1}: \mathrm{PC}_{71} \mathrm{BM}$ blend, the easiest pathway for $T_{1 \rho \mathrm{H}}$ relaxation of $\mathrm{PC}_{71} \mathrm{BM}$ occurs via the polymer, as indicated by the value of $3.6 \mathrm{~ms}$ for $T_{1 \mathrm{pH}}{ }^{\mathrm{L}}$, which is quite similar to the value for the pure $\mathbf{P 1}$ polymer film ( $3.3 \mathrm{~ms})$. This indicates that there is close contact between the polymer and fullerene at a distance of about $3 \mathrm{~nm}$. For the other blends (P2-P6:PC ${ }_{71} \mathrm{BM}$ ), the values of $T_{1 \mathrm{pH}}{ }^{\mathrm{L}}$ are significantly longer as compared to the values of the pure polymers, implying that not all of the excited $\mathrm{PC}_{71} \mathrm{BM}$ proton spins have polymer chains in their close vicinity. This means that fullerene demixing and crystallization ( $P C_{71} \mathrm{BM}$ crystals have a $T_{1 \mathrm{pH}} \mathrm{L}$ of $13 \mathrm{~ms}$; Table 2) starts to take place into phase-separated domains with estimated dimensions between 5 and $45 \mathrm{~nm}$ (calculated by the SD equation and values of $8 \mathrm{~ms}$ for $T_{1 \rho \mathrm{pH}} \mathrm{L}$ and $0.8 \mathrm{~s}$ for $T_{1 \mathrm{H}}$ ), resulting in polymer-rich and $\mathrm{PC}_{71} \mathrm{BM}$-rich phase. Since the $T_{1 \mathrm{p} \mathrm{H}^{\mathrm{L}}}$ decay time of molecularly mixed $\mathrm{PC}_{71} \mathrm{BM}$ is only around $3.5 \mathrm{~ms}$ (as for $\mathrm{P1}: \mathrm{PC}_{71} \mathrm{BM}$ ), the proton contribution of $\mathrm{PC}_{71} \mathrm{BM}$ in polymer-rich domains ends up in the $T_{1 \rho \mathrm{H}} \mathrm{s}$ fraction (since $3.5 \mathrm{~ms}$ is closer to $1 \mathrm{~ms}$ (as for the polymers) than to $13 \mathrm{~ms}$ (as for crystalline $\mathrm{PC}_{71} \mathrm{BM}$ ). The behavior of the $\mathbf{P 2}: \mathrm{PC}_{71} \mathrm{BM}, \mathrm{P5}: \mathrm{PC}_{71} \mathrm{BM}$ and P6:PC ${ }_{71} \mathrm{BM}$ blends is rather similar. In accordance to the $\mathrm{SEQE}$ results, the NMR results confirm that the degree of phase separation is clearly highest for the $\mathrm{P3}: \mathrm{PC}_{71} \mathrm{BM}$ blend, leading to a large $T_{1 \rho \mathrm{p}} \mathrm{L}$ value of $10 \mathrm{~ms}$ which is close to the value of $13 \mathrm{~ms}$ as measured for $\mathrm{PC}_{71} \mathrm{BM}$ crystals. This can explain the significant loss in $J_{s c}$ as observed in these photovoltaic devices (Table 1 ). The observed trends for the $T_{1 \rho \mathrm{H}}$ relaxation decay times and their fractions are graphically presented in Figure 5. 
(a)

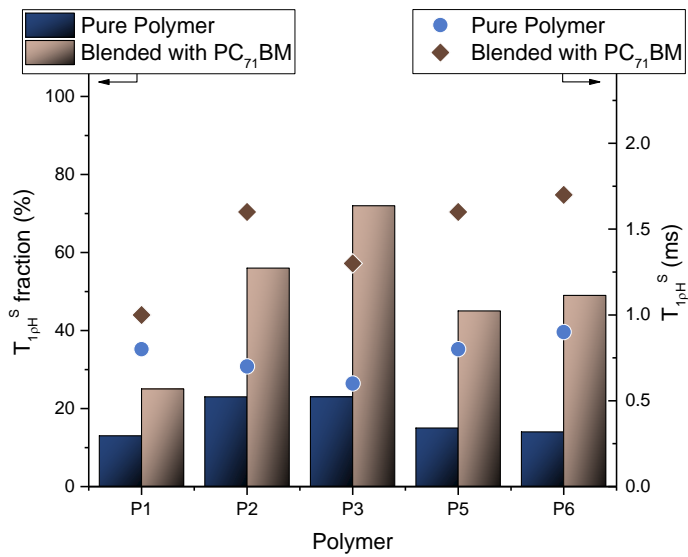

(b)

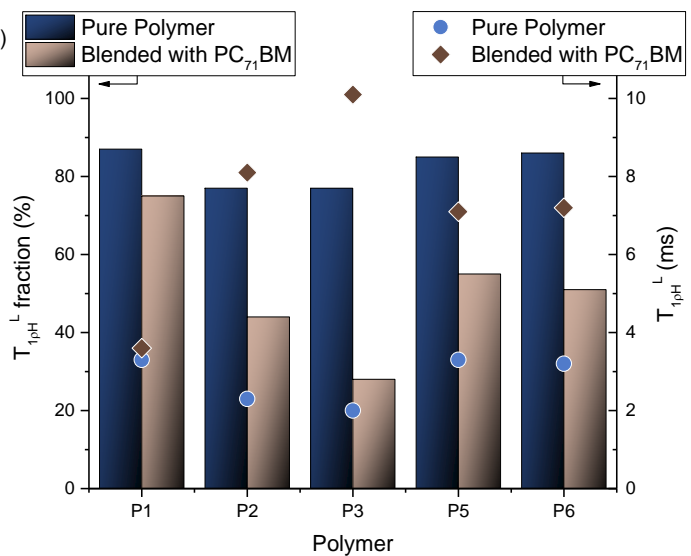

Figure 5: Illustration of the bi-exponential behavior of the spin-lattice relaxation in the rotating frame $\left(T_{1 \rho \mathrm{H}}\right)$ : (a) short decay times and their relative fractions, (b) long decay times and their relative fractions for the pure (blue bars and circles) and blend samples (grey bars and diamonds).

\section{Conclusions}

We have shown that increasing the spatial accessibility of the electron-deficient building block in a push-pull type copolymer toward fullerene 'docking' is not an infallible approach to increase charge transfer and charge separation in bulk heterojunction organic photovoltaics. A significant reduction of the power conversion efficiency was observed for PBDTTPD polymers in which the standard octyl side chain on the TPD monomer was replaced by the smaller methyl group. This reduction was most pronounced for the polymer fully decorated with 3-butylnonyl side chains on the BDT monomer to ensure proper processability. Even strongly limiting the ratio of methyl groups on the TPD moieties (to $10 \%$ and $20 \%$ ) led to a significant efficiency loss. Although AFM measurements hinted at a disturbed morphology in some of the underperforming films, it is often difficult to objectively relate the visual image to the performance of the photovoltaic device. The use of SEQE and proton wideline sSNMR relaxometry, however, indicated suboptimal molecular arrangements between the worse performing donor polymers and the fullerene molecules. Both techniques were shown to be suitable methods, complementary to existing microscopic and $\mathrm{x}$-ray diffraction techniques, to estimate the extent of molecular interface and phase separation on the nanometer scale in state-of-the-art bulk heterojunction polymer solar cell blends, and to explain the observed trends in the photovoltaic parameters (notably $J_{s c}$ ).

\section{Acknowledgements}

This work is supported by Hasselt University and the Research Foundation - Flanders (FWO Vlaanderen; project G.0B27.18N). J. Kesters and P. Verstappen are postdoctoral fellows of the FWO Vlaanderen. The authors thank $\mathrm{H}$. Penxten for the CV measurements. 


\section{Appendix A. Supplementary Data}

Supplementary data to this article - experimental details concerning the synthesis and characterization (GPC, CV, UV-Vis, DSC) of the polymer materials, additional data on the solar cell fabrication and analysis (materials and methods, optimization table, EQE), and experimental details on the ssNMR relaxometry measurements - can be found online at https://doi.org/10.1016/...

\section{References}

[1] S. Holliday, Y.L. Li, C.K. Luscombe, Recent advances in high performance donor-acceptor polymers for organic photovoltaics, Prog. Polym. Sci., 70 (2017) 34-51.

[2] Q. Wang, Y. Xie, F. Soltani-Kordshuli, M. Eslamian, Progress in emerging solution-processed thin film solar cells - Part I: Polymer solar cells, Renewable and Sustainable Energy Reviews, 56 (2016) 347-361.

[3] H. Kang, G. Kim, J. Kim, S. Kwon, H. Kim, K. Lee, Bulk-Heterojunction Organic Solar Cells: Five Core Technologies for Their Commercialization, Adv Mater, 28 (2016) 7821-7861.

[4] C. Liu, K. Wang, X. Gong, A.J. Heeger, Low bandgap semiconducting polymers for polymeric photovoltaics, Chem Soc Rev, 45 (2016) 4825-4846.

[5] C. Yan, S. Barlow, Z. Wang, H. Yan, A.K.Y. Jen, S.R. Marder, X. Zhan, Non-fullerene acceptors for organic solar cells, Nat. Rev. Mater., 3 (2018) 18003.

[6] S. Li, Z. Zhang, M. Shi, C.Z. Li, H. Chen, Molecular electron acceptors for efficient fullerene-free organic solar cells, Phys. Chem. Chem. Phys., 19 (2017) 3440-3458.

[7] J. Hou, O. Inganäs, R.H. Friend, F. Gao, Organic solar cells based on non-fullerene acceptors, Nat. Mater, 17 (2018) 119-128.

[8] S. Li, L. Ye, W. Zhao, H. Yan, B. Yang, D. Liu, W. Li, H. Ade, J. Hou, A Wide Band Gap Polymer with a Deep Highest Occupied Molecular Orbital Level Enables 14.2\% Efficiency in Polymer Solar Cells, J. Am. Chem. Soc, (2018) 7159-7167.

[9] L. Meng, Y. Zhang, X. Wan, C. Li, X. Zhang, Y. Wang, X. Ke, Z. Xiao, L. Ding, R. Xia, H.L. Yip, Y. Cao, Y. Chen, Organic and solution-processed tandem solar cells with $17.3 \%$ efficiency, Science, (2018) 10941098.

[10] J. Yuan, Y. Zhang, L. Zhou, G. Zhang, H.-L. Yip, T.-K. Lau, X. Lu, C. Zhu, H. Peng, P.A. Johnson, M. Leclerc, Y. Cao, J. Ulanski, Y. Li, Y. Zou, Single-Junction Organic Solar Cell with over 15\% Efficiency Using Fused-Ring Acceptor with Electron-Deficient Core, Joule, (2019).

[11] E. Buchaca-Domingo, K. Vandewal, Z. Fei, S.E. Watkins, F.H. Scholes, J.H. Bannock, J.C. de Mello, L.J. Richter, D.M. DeLongchamp, A. Amassian, M. Heeney, A. Salleo, N. Stingelin, Direct Correlation of Charge Transfer Absorption with Molecular Donor:Acceptor Interfacial Area via Photothermal Deflection Spectroscopy, J Am Chem Soc, 137 (2015) 5256-5259.

[12] K. Vandewal, J. Widmer, T. Heumueller, C.J. Brabec, M.D. McGehee, K. Leo, M. Riede, A. Salleo, Increased open-circuit voltage of organic solar cells by reduced donor-acceptor interface area, Adv Mater, 26 (2014) 3839-3843.

[13] K. Schmidt-Rohr, H. Spiess, Multidimensional solid-state NMR and polymers Academic Press1996.

[14] J. Clauss, K. Schmidt-Rohr, H.W. Spiess, Determination of domain sizes in heterogeneous polymers by solid-state NMR, Acta Polymerica, 44 (1993) 1-17. 
[15] V.D. Fedotov, H. Schneider, Structure and Dynamics of Bulk Polymers by NMR-Methods Springer-Verlag1989.

[16] A. Dukic, R. Mens, P. Adriaensens, P. Foreman, J. Gelan, J.P. Remon, C. Vervaet, Development of starch-based pellets via extrusion/spheronisation, Eur J Pharm Biopharm, 66 (2007) 83-94.

[17] S. D'hollander, C.J. Gommes, R. Mens, P. Adriaensens, B. Goderis, F. Du Prez, Modeling the morphology and mechanical behavior of shape memory polyurethanes based on solid-state NMR and synchrotron SAXS/WAXD, Journal of Materials Chemistry, 20 (2010) 3475-3486.

[18] R. Mens, P. Adriaensens, L. Lutsen, A. Swinnen, S. Bertho, B. Ruttens, J. D'Haen, J. Manca, T. Cleij, D. Vanderzande, J. Gelan, NMR study of the nanomorphology in thin films of polymer blends used in organic PV devices: MDMO-PPV/PCBM, Journal of Polymer Science Part A: Polymer Chemistry, 46 (2008) 138-145.

[19] R. Mens, S. Bertho, S. Chambon, J. D'Haen, L. Lutsen, J. Manca, J. Gelan, D. Vanderzande, P. Adriaensens, Solid-state NMR as a tool to describe and quantify the morphology of photoactive layers used in plastic solar cells, Journal of Polymer Science Part A: Polymer Chemistry, 49 (2011) 1699-1707.

[20] R.C. Nieuwendaal, C.R. Snyder, R.J. Kline, E.K. Lin, D.L. VanderHart, D.M. DeLongchamp, Measuring the Extent of Phase Separation in Poly-3-Hexylthiophene/Phenyl-C61-Butyric Acid Methyl Ester Photovoltaic Blends with1H Spin Diffusion NMR Spectroscopy, Chemistry of Materials, 22 (2010) 2930-2936.

[21] R.C. Nieuwendaal, H.W. Ro, D.S. Germack, R.J. Kline, M.F. Toney, C.K. Chan, A. Agrawal, D. Gundlach, D.L. VanderHart, D.M. Delongchamp, Measuring Domain Sizes and Compositional Heterogeneities in P3HT-PCBM Bulk Heterojunction Thin Films with 1H Spin Diffusion NMR Spectroscopy, Advanced Functional Materials, 22 (2012) 1255-1266.

[22] R.C. Nieuwendaal, D.M. DeLongchamp, L.J. Richter, C.R. Snyder, R.L. Jones, S. Engmann, A. Herzing, M. Heeney, Z. Fei, A.B. Sieval, J.C. Hummelen, Characterization of Interfacial Structure in Polymer-Fullerene Bulk Heterojunctions via $\wedge\{13\} C\{\wedge\{2\} \mathrm{H}\}$ Rotational Echo Double Resonance NMR, Phys Rev Lett, 121 (2018) 026101.

[23] S. Chambon, R. Mens, K. Vandewal, E. Clodic, M. Scharber, L. Lutsen, J. Gelan, J. Manca, D. Vanderzande, P. Adriaensens, Influence of octanedithiol on the nanomorphology of PCPDTBT:PCBM blends studied by solid-state NMR, Solar Energy Materials and Solar Cells, 96 (2012) 210-217.

[24] C. Risko, M.D. McGehee, J.-L. Brédas, A quantum-chemical perspective into low optical-gap polymers for highly-efficient organic solar cells, Chem. Sci., 2 (2011) 1200-1218.

[25] K.R. Graham, C. Cabanetos, J.P. Jahnke, M.N. Idso, A. El Labban, G.O. Ngongang Ndjawa, T. Heumueller, K. Vandewal, A. Salleo, B.F. Chmelka, A. Amassian, P.M. Beaujuge, M.D. McGehee, Importance of the donor:fullerene intermolecular arrangement for high-efficiency organic photovoltaics, J Am Chem Soc, 136 (2014) 9608-9618.

[26] P. Verstappen, J. Kesters, L. D'Olieslaeger, J. Drijkoningen, I. Cardinaletti, T. Vangerven, B.J. Bruijnaers, R.E.M. Willems, J. D'Haen, J.V. Manca, L. Lutsen, D.J.M. Vanderzande, W. Maes, Simultaneous Enhancement of Solar Cell Efficiency and Stability by Reducing the Side Chain Density on Fluorinated PCPDTQx Copolymers, Macromolecules, 48 (2015) 3873-3882.

[27] H. Yao, L. Ye, H. Zhang, S. Li, S. Zhang, J. Hou, Molecular Design of Benzodithiophene-Based Organic Photovoltaic Materials, Chem Rev, 116 (2016) 7397-7457.

[28] C. Cabanetos, A. El Labban, J.A. Bartelt, J.D. Douglas, W.R. Mateker, J.M. Frechet, M.D. McGehee, P.M. Beaujuge, Linear side chains in benzo[1,2-b:4,5-b']dithiophene-thieno[3,4-c]pyrrole4,6-dione polymers direct self-assembly and solar cell performance, J Am Chem Soc, 135 (2013) 4656-4659. 
[29] A. Tournebize, J.-L. Gardette, C. Taviot-Guého, D. Bégué, M.A. Arnaud, C. Dagron-Lartigau, H. Medlej, R.C. Hiorns, S. Beaupré, M. Leclerc, A. Rivaton, Is there a photostable conjugated polymer for efficient solar cells?, Polymer Degradation and Stability, 112 (2015) 175-184.

[30] R. Po, G. Bianchi, C. Carbonera, A. Pellegrino, "All That Glisters Is Not Gold": An Analysis of the Synthetic Complexity of Efficient Polymer Donors for Polymer Solar Cells, Macromolecules, 48 (2015) 453-461.

[31] G. Pirotte, J. Kesters, P. Verstappen, S. Govaerts, J. Manca, L. Lutsen, D. Vanderzande, W. Maes, Continuous Flow Polymer Synthesis toward Reproducible Large-Scale Production for Efficient Bulk Heterojunction Organic Solar Cells, ChemSusChem, 8 (2015) 3228-3233.

[32] C. Piliego, T.W. Holcombe, J.D. Douglas, C.H. Woo, P.M. Beaujuge, J.M. Frechet, Synthetic control of structural order in N-alkylthieno[3,4-c]pyrrole-4,6-dione-based polymers for efficient solar cells, J Am Chem Soc, 132 (2010) 7595-7597.

[33] Y. Zou, A. Najari, P. Berrouard, S. Beaupre, B.R. Aich, Y. Tao, M. Leclerc, A thieno[3,4-c]pyrrole4,6-dione-based copolymer for efficient solar cells, J Am Chem Soc, 132 (2010) 5330-5331.

[34] A. El Labban, J. Warnan, C. Cabanetos, O. Ratel, C. Tassone, M.F. Toney, P.M. Beaujuge, Dependence of crystallite formation and preferential backbone orientations on the side chain pattern in PBDTTPD polymers, ACS Appl Mater Interfaces, 6 (2014) 19477-19481.

[35] C. Dyer-Smith, I.A. Howard, C. Cabanetos, A. El Labban, P.M. Beaujuge, F. Laquai, Interplay Between Side Chain Pattern, Polymer Aggregation, and Charge Carrier Dynamics in PBDTTPD:PCBM Bulk-Heterojunction Solar Cells, Advanced Energy Materials, 5 (2015).

[36] J. Hou, M.-H. Park, S. Zhang, Y. Yao, L.-M. Chen, J.-H. Li, Y. Yang, Bandgap and Molecular Energy Level Control of Conjugated Polymer Photovoltaic Materials Based on Benzo[1,2-b:4,5-

b']dithiophene, Macromolecules, 41 (2008) 6012-6018.

[37] K. Vandewal, Interfacial Charge Transfer States in Condensed Phase Systems, Annu Rev Phys Chem, 67 (2016) 113-133.

[38] R. Mens, S. Chambon, S. Bertho, G. Reggers, B. Ruttens, J. D'Haen, J. Manca, R. Carleer, D. Vanderzande, P. Adriaensens, Description of the nanostructured morphology of [6,6]-phenyl-C61 butyric acid methyl ester (PCBM) by XRD, DSC and solid-state NMR, Magn Reson Chem, 49 (2011) 242-247.

[39] P. Adriaensens, H. Roex, D. Vanderzande, J. Gelan, Study of the thermal elimination process of sulphinyl-based PPV precursors by solid state NMR, Polymer, 46 (2005) 1759-1765. 